\title{
Finanzpolitische Leitlinien: zwischen Bidenomics und Schuldenbremse
}

Mit der bevorstehenden Bundestagswahl öffnet sich ein neues Möglichkeitsfenster für die Finanzpolitik in Deutschland. Vertreter:innen unterschiedlicher Parteien machen sich dafür stark, die Finanzpolitik neu auszurichten. Mit US-Präsident Biden ist es in den USA bereits zu neuen Weichenstellungen beispielsweise auf den Gebieten Klimapolitik und Steuerwettbewerb gekommen. Diese dürften direkte Auswirkungen auf die Politik in Europa haben. Dabei stellt sich die spannende Frage, welche Lehren aus der wirtschafts- und finanzpolitischen Neuausrichtung in den USA für die deutsche Wirtschaftspolitik gezogen werden können.

\section{Bidens Fiskalpolitik - ein Vorbild für Deutschland?}

Rüdiger Bachmann, University of Notre Dame in den USA.

\section{Zukunftsperspektiven sichern durch Reformen, nicht durch Schulden}

Lars P. Feld, Walter Eucken Institut; Albert-Ludwigs-Universität Freiburg; Sachverständigenrat zur Begutachtung der gesamtwirtschaftlichen Entwicklung.

Veronika Grimm, Alexander-Universität Erlangen-Nürnberg; Sachverständigenrat zur Begutachtung der gesamtwirtschaftlichen Entwicklung.

Wolf Heinrich Reuter, Sachverständigenrat zur Begutachtung der gesamtwirtschaftlichen Entwicklung.

In der Fiskalpolitik sind Grundsatzentscheidungen notwendig

Jens Südekum, Heinrich-Heine-Universität Düsseldorf.

Steuerliche Aspekte der Klimapolitik: über Steuern, Zölle und Subventionen

Gabriel Felbermayr, Institut für Weltwirtschaft Kiel. 